\title{
The Formed Voids around the Filler Particles Impact on the Mixed Matrix Membranes' Gas Permeabilities
}

\author{
O. Bakhtiari and N. Sadeghi
}

\begin{abstract}
In real structures of mixed matrix membranes (MMMs), voids may be formed around the filler particles due to detachment of polymer chain's from the filler particles' surface. Some general predictive models such as Maxwell, Bruggeman, and Pal, have been employed to predict the permeabilities of this type of MMMs with incorporated nonporous particles. Calculated AAREs were high as 11.1, 54.8, 25.4\%. In this article, predictive permeation models were modified to improve prediction accuracy of these models by introduction of beta parameter, $\beta$. This parameter is introduced due to overestimation of employed Knudsen mechanism for prediction of the formed voids around the filler particles' permeability. After this introduction, AAREs of the modified Maxwell, Bruggeman, and Pal models were reduced to 8.4, 46.6, and 21.9 \%, respectively. On the other hand, selectivities' AAREs were also considerably reduced after introduction of the $\beta$ parameter: from 54.9, 303.6, 67.7 to $5.1,35,34.5$ for the modified Maxwell, Bruggeman, and Pal models, respectively.
\end{abstract}

Index Terms-Mixed matrix membrane, permeation prediction, predictive models, void formation.

\section{INTRODUCTION}

During the past decades, membranes have attracted more attention in various types of liquid and gas based separations due to relatively low capital cost, compact structure, low energy demand, ease of operation and recent industrial applications such as hydrogen production, nitrogen recovery from air and natural gas purification survey, etc. [1]-[3]. Fig. 1 provides a summary of the development of gas separation technology [3]. Mixed matrix membranes (MMMs) represent next-generation gas separation membranes that integrate the outstanding separation properties of molecular sieves (zeolites, carbon molecular sieves, etc.) with the cost and processing advantages of polymers [4]. Generally speaking, MMMs are based on solid-solid system comprised of inorganic dispersed phase inserted in a polymer matrix.

These kinds of membranes have the potential to achieve higher selectivity, permeability, or both relative to the existing polymeric membranes, resulting from the addition of the inorganic particles with their inherent superior separation characteristics [5]. Successful development of these materials would provide a solution to the well-known permeability/selectivity trade off observed for polymer membranes [4]. Schematic of a mixed matrix membrane is shown in Fig. 2 [6].

Manuscript received October 31, 2013; revised December 14, 2013 The authors are with the Chemical Engineering Department, Faculty of Engineering, Razi University, Kermanshah, Iran (e-mail: omidbakhtiari@iust.ac.ir, n_sadeghi_67@yahoo.com).

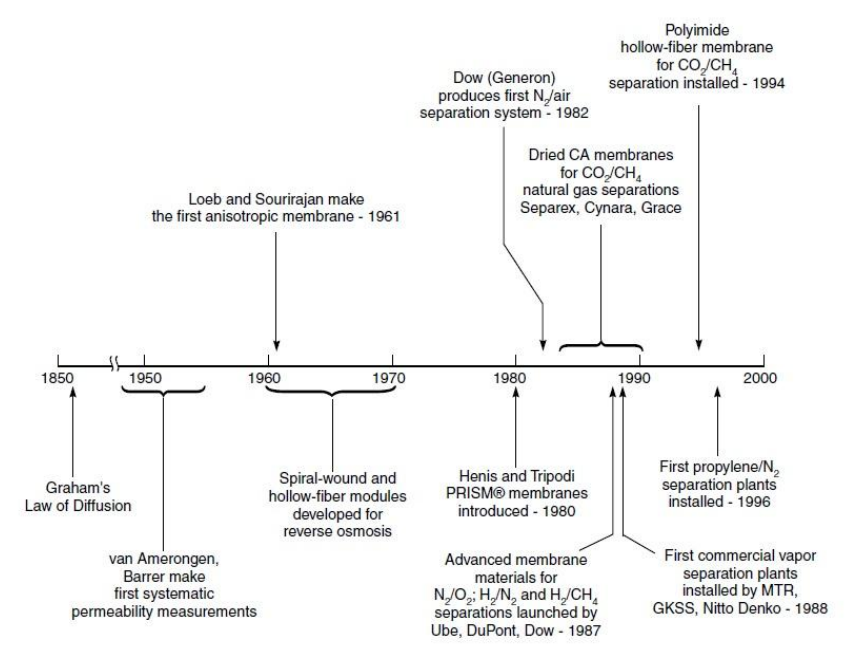

Fig. 1. Milestones in the development of gas separation [3].

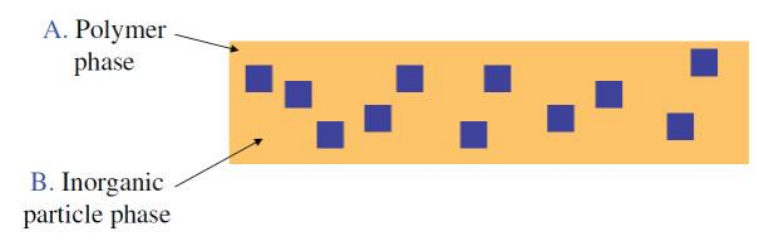

Fig. 2. Schematic of Mixed Matrix Membrane [6].

In an ideal MMM structure, polymeric chains come into intimate contact on filler particles surface with clearly distinguishable interface. However, in many real structures of MMMs due to the different properties of the (inorganic) filler particles and polymer matrices, some non-ideal morphologies (defects) such as filler particles pore blockage, polymer chains' rigidification and/or interface void formation may occur during MMMs preparation, as shown in Fig. 3 [6]. Case 1 presents ideal (defect-free) morphology of filler particles-polymer chains' interface. Case 2 indicates poor adhesion between filler particles and polymer chains' which causes the void formation around the filler particles. De-wetting of polymer chains from filler particles surface during MMM preparation due to drying stresses and their detachments result in polymer packing disruption in the vicinity of the filler particles and void formation around them. Case 3 shows a region of rigidified polymer chains in direct contact with the filler particles surface in which mobilities of attached polymer chains are reduced compared to those are in polymer matrix. Case 4 corresponds to a situation named filler particles pore blockage which the surface pores have been partially or totally blocked by entered polymer chains. It seems that the frequently case is void formation which results in the MMMs permeabilities increment while selectivities decreased [7]-[10]. 


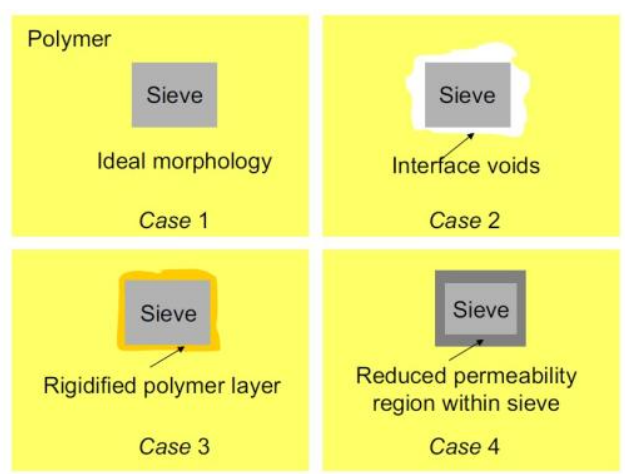

Fig. 3. Schematic representation of different possible MMMs morphology in vicinity of filler particles [6].

For the effective design and optimum operating condition of a MMM separation process, understanding of the permeabilities of different gas penetrants is vital [11]. Moreover, modeling of the permeability of MMMs is of great interest as these materials have high technological importance in gas separation processes [12]. The general concept of gas permeation through mixed matrix membranes is shown in Fig. 4 [11].

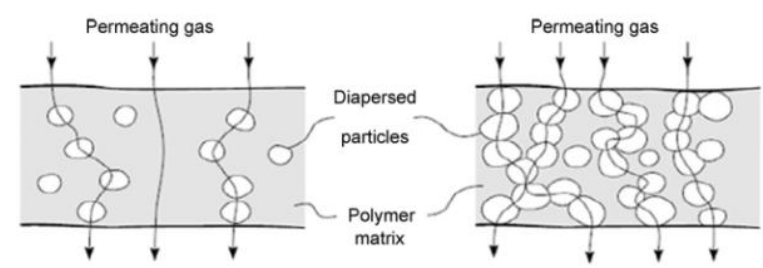

Fig. 4. Gas permeation through mixed-matrix membranes [11].

In this paper, the existing models for permeation in MMMs are first reviewed, albeit briefly. A new improved model to predict the permeability of penetrants in a MMM is then proposed and evaluated using the available experimental data.

\section{Some Developed MMMs' SeParation Performance MODELS}

The existing models for MMMs' separation performance through MMMs have been developed based on analogies between thermal/electrical conduction in composite materials and gaseous penetrants permeation through MMMs [13]. Maxwell model was originally developed for electrical conductivity of particulate composite in 1873 and then employed for MMMs' separation performance prediction in 1997 as the following equation [14]-[15]:

$$
P_{r}=\frac{P_{M M M}}{P_{C}}=\frac{P_{d}+2 P_{C}-2 \phi_{d}\left(P_{C}-P_{d}\right)}{P_{d}+2 P_{C}+\phi_{d}\left(P_{C}-P_{d}\right)}
$$

where $P_{r}$ is the permeability ratio $P_{M M M} / P_{c}, P_{M M M}, P_{c}$ and $P_{d}$ are permeabilities of MMMs, polymer (continuous phase) and filler particles (disperse phase), respectively and $P_{d}$ is volume fraction of the dispersed phase. Maxwell model is an explicit easy to solve equation for MMMs permeability prediction. Nevertheless, the effects of filler particle size distribution, shape, and aggregation are not considered. In addition Maxwell model is not valid for maximum filler volume fraction [9], [15].

The Bruggeman model, originally was developed for prediction of particulate composites' dielectric constant and was adapted for MMMs' permeability prediction over a wide range of filler particles loading as the following equation [15]:

$$
\left(\frac{\left(P_{M M M} / P_{C}\right)-\left(P_{d} / P_{C}\right)}{1-\left(P_{d} / P_{C}\right)}\right)\left(\frac{P_{M M M}}{P_{C}}\right)^{-1 / 3}=1-\phi_{d}
$$

Similar to the Maxwell model, the Bruggeman model ignores the effects of filler particle shape, size distribution and aggregation. The Bruggeman model is an implicit relationship that needs to be solved numerically for $P_{M M M}$ [9], [15].

The Pal model, originally was used for prediction of particulate composites' thermal conductivity and also employed for predicting MMMs permeability as the following equation [15], [16].

$$
\left(\frac{\left(\boldsymbol{P}_{d} / \boldsymbol{P}_{c}\right)-1}{\left(\boldsymbol{P}_{d} / \boldsymbol{P}_{C}\right)-\left(\boldsymbol{P}_{\text {ммм }} / \boldsymbol{P}_{c}\right)}\right) \times\left(\frac{\boldsymbol{P}_{M M M}}{\boldsymbol{P}_{C}}\right)^{1 / 3}=\left(1-\frac{\boldsymbol{\phi}}{\boldsymbol{\phi}_{m}}\right)^{-\boldsymbol{\phi}_{m}}
$$

where ${ }_{\phi_{m}}$ is the maximum packing volume fraction of filler particles which is 0.64 for random close packing of uniform spheres. Note that when $\phi_{m} \rightarrow 1$, the model reduces to the Bruggeman model. The effect of morphology is taking to

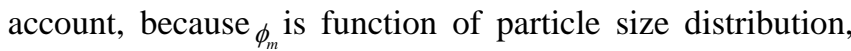
particle shape, and aggregation of particles. Like Bruggeman model, this model is an implicit relationship that needs to be solved numerically [9], [11].

There are many other models available for the prediction of gas permeation in MMMs. Among them, Maxwell, Bruggeman, Pal, Lewis-Nielsen and Fleske models are the most famous and selected for further analysis and comparison [11].

\section{Models AND Methods For MMMs' PeRMEABILITY PREDICTION WITH THE FORMED VOIDS AROUND THE FILLER PARTICLE}

The formed voids around the incorporated filler particles in MMMs structure can be considered as a third phase with its own separation properties. The void permeability can be estimated using Knudsen flow through formed voids. In this approach, formed voids' gas permeability, $P_{I}$, is considered as the product of modified Knudsen diffusion, $D$, and molecular solubility (concentration), $S$, in formed voids as following equations [1]:

$$
\begin{gathered}
P_{I}=D S \\
D=D_{\text {Knudsen }}\left(1-\frac{\sigma}{2 l_{I}}\right)
\end{gathered}
$$

where

$$
D=D_{\text {Knudsen }}=\left(d_{\text {pore }} / 3\right)\left(8 R T / \pi M_{I}\right)^{1 / 2}
$$




$$
S=\frac{1}{R T}\left(1-\frac{\sigma}{2 l_{I}}\right)^{2}
$$

where $\sigma_{p}$ is Lennard-Jones diameter of gaseous penetrant, $l_{I}$ is effective thickness of the formed void around the filler particles, $d_{\text {Pore }}$ is pore diameter which approximated as $2 l_{I}, R$ is the universal gas constant, $\mathrm{T}$ is absolute temperature and $M_{I}$ is the molecular weight of penetrant.

Now, the "effective filler particles permeability, $P_{\text {eff, }}$, can be estimated using a proper MMMs permeability prediction model, e.g. the Maxwell model, by considering filler particles as incorporated within a pseudo-continuous phase of the formed voids [17]:

$$
\begin{gathered}
P_{e f f}=P_{I}\left(\frac{P_{d}+2 P_{I}-2 \phi_{S}\left(P_{I}-P_{d}\right)}{P_{d}+2 P_{I}+\phi_{S}\left(P_{I}-P_{d}\right)}\right) \\
\phi_{S}=\frac{\phi_{d}}{\phi_{d}+\phi_{I}}=\left(\frac{r_{d}}{r_{d}+l_{I}}\right)^{3}
\end{gathered}
$$

where ${ }_{\varphi_{S}}$ is volume fraction of the filler particles in the formed voids, $r_{d}$ is average filler particles' radius and $\varphi_{I}$ is the volume fraction of the formed voids in the total MMM volume.

After estimation of fillers particles effective permeability, the selected predictive model of Maxwell is used again to estimate MMM permeability as the following equation [8], [11], [18]:

$$
P_{M M M}=P_{C}\left(\frac{P_{e f f}+2 P_{C}-2\left(\phi_{d}+\phi_{I}\right)\left(P_{C}-P_{e f f}\right)}{P_{e f f}+2 P_{C}+\left(\phi_{d}+\phi_{I}\right)\left(P_{C}-P_{e f f}\right)}\right)
$$

This two steps Maxwell model is shown schematically in Fig. 5. [11].
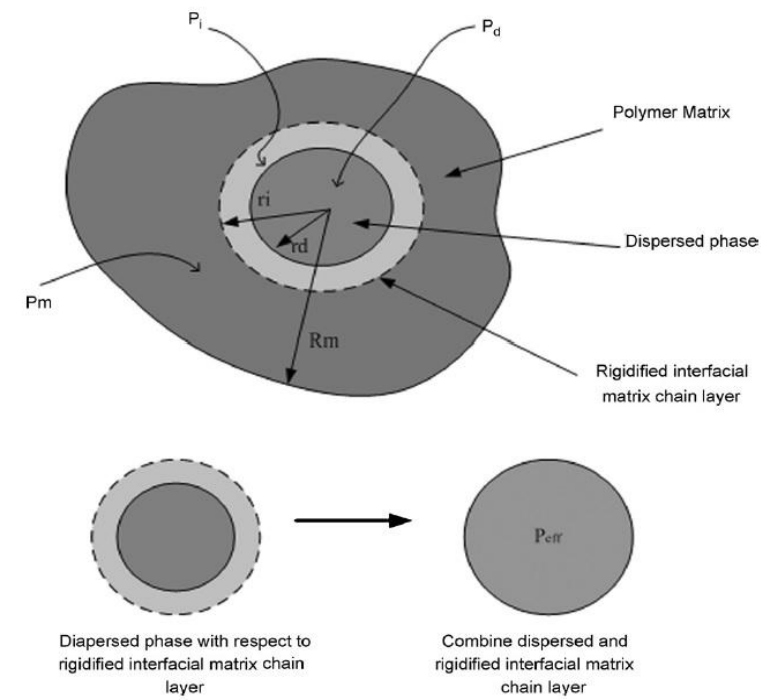

Fig. 5. Schematic representation of the two steps Maxwell model for prediction of a real MMM permeability with the formed voids around the filler particles [11].

The estimated permeabilities by this approach for the formed voids is seems to be high (Fig. 6) and also is higher than that reported A.B. Shelekhin et al. (Fig. 7) [19], it seems that these permeabilities should be corrected. This correction is carried out by a parameter of void permeability adjustment, $\beta$, in current study. Taking into the account with the first parameter of $l_{l}$, the model seems to becomes more accurate after introduction of the second parameters of $\beta$. In the following section, the impact of this parameter introduction will be discussed.

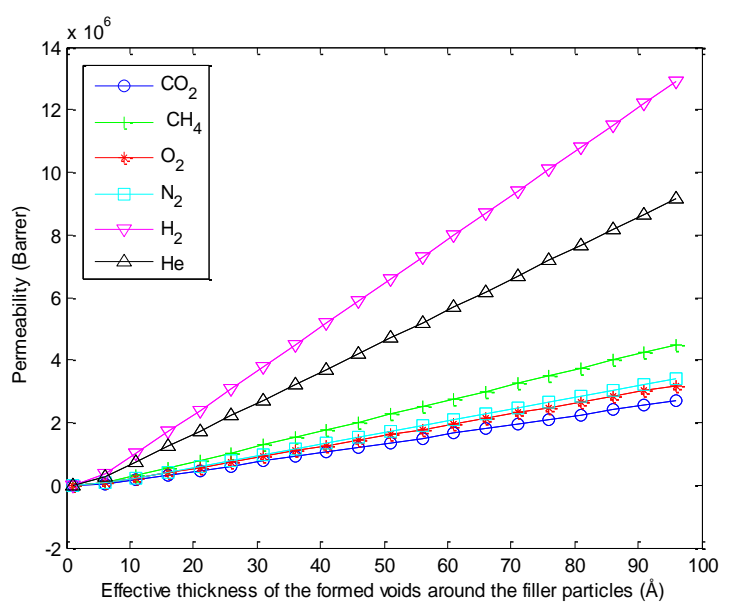

Fig. 6. Calculated permeability of the formed voids vs. void effective thickness based on Knudsen flow.

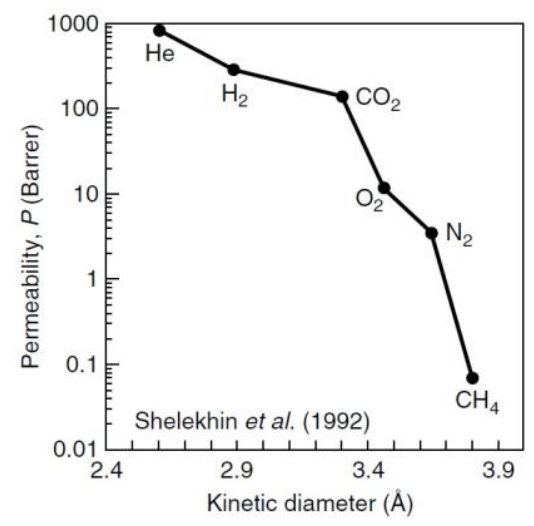

Fig. 7. Permeability of different gaseous penetrants in silica hollow fine fibers with average pore size of $20 \mu \mathrm{m}$ [19].

In this manner, permeabilities of three phases of species in polymer matrix, void space and filler particles is included in prediction of MMMs' permeability in two-step approach [1]. Absolutely the only variable that can affects the MMMs' permeability is $l_{I}$ The optimum value of $l_{I}$ is determined by least square method, e.g. minimum $S$ in the following equation:

$$
S=\sum_{i=1}^{N}\left(P_{i}^{c a l}-P_{i}^{\exp }\right)^{2}
$$

where $P_{i}^{\text {cal }}$ and $P_{i}^{\text {exp }}$ are the calculated and experimental measured MMMs' permeabilities at a certain filler particle loading. After calculation of MMMs' optimum permeabilities, absolute average relative error percentage (AARE \%) is calculated with the following equation [11]:

$$
A A R E \%=\frac{100}{N} \sum_{i=1}^{N}\left|\frac{P_{i}^{c a l}-P_{i}^{\exp }}{P_{i}^{\exp }}\right|
$$

where $N$ is the number of experimental data points. 


\section{RESUlTS AND DisCUSSION}

Some experimental measured MMMs' permeabilities were gathered in proper published papers (Table I). Developed model and current modified proposed model are employed to predict the permeability and selectivity of these experimental data.

TABLE I: EXPERIMENTAL MEASURED PERMEABILITY OF DIFFERENT MMMS

\begin{tabular}{|c|c|c|c|c|}
\hline \multirow[t]{2}{*}{ MMM } & \multirow[t]{2}{*}{$\varphi_{d}$} & \multicolumn{2}{|c|}{$\begin{array}{c}\text { Permeability } \\
\text { (Barrer) }\end{array}$} & \multirow{2}{*}{$\begin{array}{c}\text { MMMs Ideal } \\
\text { Selectivity } \\
\alpha_{\mathrm{O}_{2 / \mathrm{N} 2}}\end{array}$} \\
\hline & & $P_{\mathrm{O}_{2}}$ & $P_{\mathrm{N}_{2}}$ & \\
\hline \multirow{4}{*}{$\begin{array}{c}\text { PCPA-Fumed } \\
\text { silica(TS530) [20] }\end{array}$} & 0 & 8.6 & 1.8 & 4.77 \\
\hline & 0.058 & 18 & 4 & 4.5 \\
\hline & 0.19 & 86 & 28 & 3.07 \\
\hline & & $P_{\mathrm{He}}$ & $P_{\mathrm{N}_{2}}$ & $\alpha_{\mathrm{He} / \mathrm{N}_{2}}$ \\
\hline \multirow{4}{*}{$\begin{array}{c}\text { PCPA-Fumed } \\
\text { silica(TS530) [20] }\end{array}$} & 0 & 33 & 1.8 & 18.33 \\
\hline & 0.058 & 67 & 4 & 16.75 \\
\hline & 0.019 & 220 & 28 & 7.86 \\
\hline & & $P_{\mathrm{He}}$ & $P_{\mathrm{N}_{2}}$ & $\alpha_{\mathrm{He} / \mathbf{N}_{2}}$ \\
\hline \multirow{5}{*}{$\begin{array}{l}\text { Polysulfone-Fumed } \\
\text { silica(TS530) [21] }\end{array}$} & 0 & 11.8 & 0.24 & 49.16 \\
\hline & 0.05 & 13.1 & 0.31 & 42.26 \\
\hline & 0.1 & 14.9 & 0.4 & 37.25 \\
\hline & 0.15 & 20.1 & 0.67 & 30 \\
\hline & 0.2 & 27.7 & 1.12 & 24.37 \\
\hline \multirow{7}{*}{$\begin{array}{c}\text { Matrimid- } \mathrm{TiO}_{2} \\
{[22]}\end{array}$} & & $P_{\mathrm{O}_{2}}$ & $P_{\mathrm{N}_{2}}$ & $\alpha_{\mathrm{O}_{2} / \mathrm{N}_{2}}$ \\
\hline & 0 & 1.29 & 0.22 & 5.86 \\
\hline & 0.05 & 1.6 & 0.36 & 4.44 \\
\hline & 0.1 & 1.75 & 0.5 & 3.5 \\
\hline & 0.15 & 1.86 & 0.74 & 2.51 \\
\hline & 0.2 & 2.45 & 0.92 & 2.66 \\
\hline & 0.25 & 3.25 & 1.35 & 2.41 \\
\hline
\end{tabular}

Fig. 8 shows the comparison of the predicting ability of the three available models and their modified for permeability of $\mathrm{O}_{2}, \quad \mathrm{~N}_{2}$ and the selectivity of $\mathrm{O}_{2} / \mathrm{N}_{2}$ in poly (1-chloro-2-phenylacetylen) (PCPA)-Fumed Silica (FS) mixed matrix membrane at $25{ }^{\circ} \mathrm{C}$. The predicted values and AARE $\%$ for permeability of $\mathrm{O}_{2}, \mathrm{~N}_{2}$ and $\mathrm{He}, \mathrm{N}_{2}$ in the PCPA-FS system are shown in Table II and Table III, respectively. As seen in these Tables, employing original models to predict PCPA-FS MMM performance resulted in large AARE while after introduction $\beta$, AAREs of both permeabilities and selectivity except for Bruggeman model in Table II. AARE \% for selectivities become much smaller. But one exception is in Bruggeman model for prediction of $\mathrm{O}_{2} / \mathrm{N}_{2}$, when using original model AARE $\%$ is 24.318 and after using $\beta$ it is equal to 61.206 . However should noted that the value of the $l_{I}$, which indicates the thickness of void volume layer surrounding nanoparticle, at first is $2.2 \AA$ which is smaller than diameter of the penetrating molecules. Experimental data show increasing in $\mathrm{O}_{2}, \mathrm{~N}_{2}$ permeation and decreasing in selectivity which is means void volume layer has permeation. So $l_{I}$ should be larger than penetrate diameter and it is modified after introducing $\beta$ parameter $\left(l_{I}=57.7 \AA\right)$. Also, should be noted that $\beta$ parameter is more less than one $(\beta \ll 1)$, it means void permeability was more than Knudsen flow and corrected by $\beta$ factor.

Polysulfone-Silica MMMs measured permeabilities data at $35{ }^{\circ} \mathrm{C}$ is used for comparison of different original and modified permeation predictive models' abilities. The results of this predicting are shown in Table IV. AARE $\%$ of $\mathrm{N}_{2}$ permeability and selectivity for Bruggeman model are more than 100 , after using $\beta$ parameter are reduced to acceptable values, as 40.9 and 9.3 , respectively.
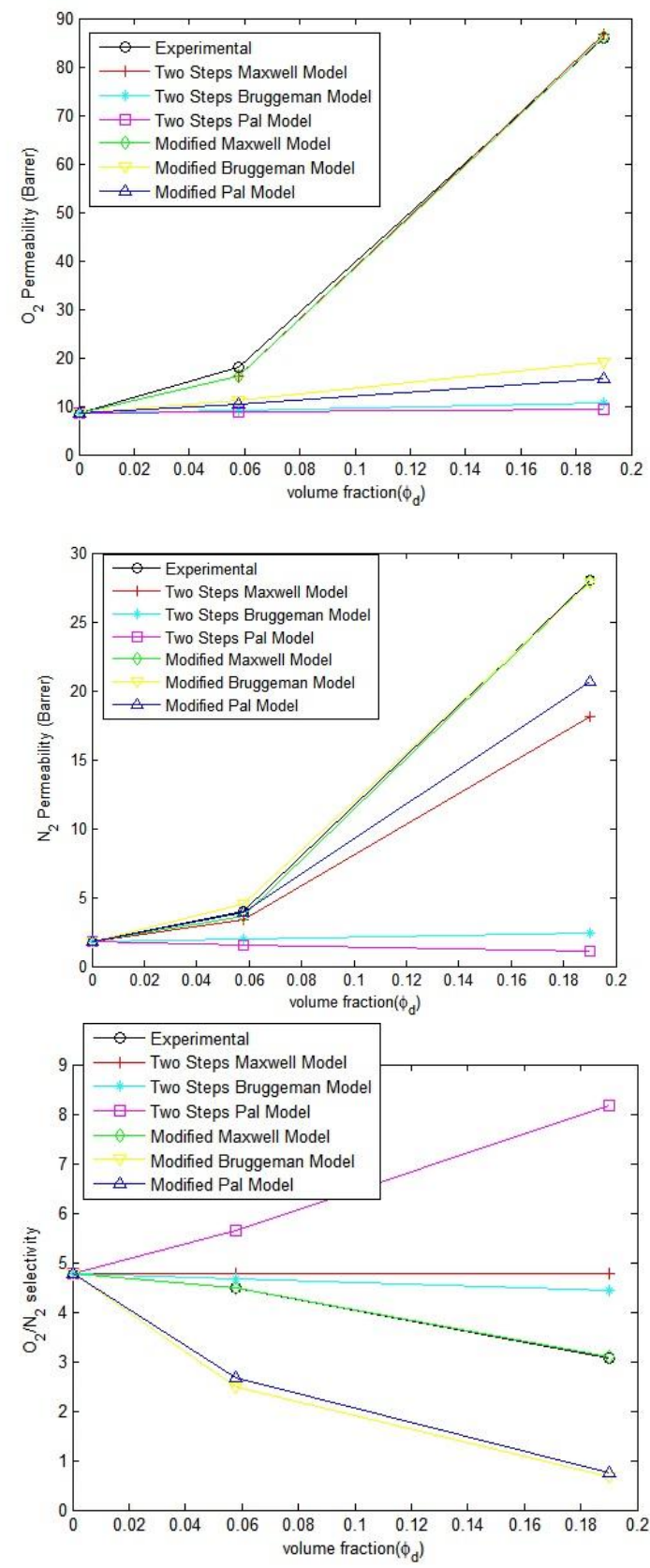

Fig. 8. Comparison of the experimental $\mathrm{O}_{2}$ and $\mathrm{N}_{2}$ permeabilities and selectivity through PCPA-FS MMMs [20]

TABLE II: COMPARISON OF THE AARE VALUES FOR IDEAL AND MODIFIED Models (USING THE EXPERIMENTAL DATA OF $\mathrm{O}_{2}, \mathrm{~N}_{2}$ PERMEATION AND $\mathrm{O}_{2} / \mathrm{N}_{2}$ SELECTIVITY IN PCPA-SiliCA MMM AT $\left.298 \mathrm{~K}\right)$ [20]

\begin{tabular}{|c|c|c|c|c|c|}
\hline \multirow{2}{*}{ Model } & \multirow{2}{*}{$l_{I}(\AA)$} & \multirow{2}{*}{$\beta$} & \multicolumn{3}{|c|}{ AARE \% } \\
\hline & & & $P_{\mathrm{O}_{2}}$ & $P_{\mathrm{N}_{2}}$ & $\alpha_{\mathrm{O}_{2} / \mathrm{N}_{2}}$ \\
\hline Maxwell & 18.9 & - & 10.508 & 14.445 & 15.771 \\
\hline $\begin{array}{c}\text { Modified Maxwell } \\
\text { Model }\end{array}$ & 42.1 & 0.00022 & 4.874 & 4.726 & 0.37 \\
\hline Bruggeman Model & 2.2 & - & 68.351 & 71.204 & 24.318 \\
\hline $\begin{array}{c}\text { Modified } \\
\text { Bruggeman Model }\end{array}$ & 57.7 & 0.000011 & 57.952 & 6.155 & 61.206 \\
\hline Pal Model & 1.9 & - & 70.165 & 78.47 & 95.871 \\
\hline Modified Pal Model & 47.5 & 0.00002 & 62.091 & 14.677 & 57.961 \\
\hline
\end{tabular}


TABLE III: COMPARISON OF THE AARE VALUES FOR IDEAL AND MODIFIED Models (Using the EXPERIMENTAl Data OF He, $\mathrm{N}_{2}$ PERMEATION AND HE/ $\mathrm{N}_{2}$ SELECTIVITY IN PCPA-SILICA MMM AT $298 \mathrm{~K}$ ) [20]

\begin{tabular}{|c|c|c|c|c|c|}
\hline \multirow{2}{*}{ Model } & \multirow{2}{*}{$\begin{array}{l}\boldsymbol{l} \\
\text { Maxwell }\end{array}$} & $\boldsymbol{\beta}$ & \multicolumn{3}{|c|}{ AARE \% } \\
\cline { 4 - 6 } & 32.7 & - & 7.179 & 39.066 & 71.381 \\
\hline Maxwel & $\boldsymbol{P}_{\mathrm{He}}$ & $\boldsymbol{P}_{\mathrm{N}_{2}}$ & $\boldsymbol{\alpha}_{\mathbf{H e}_{\mathbf{2}}}$ \\
\hline $\begin{array}{c}\text { Modified Maxwell } \\
\text { Model }\end{array}$ & 42.1 & $\begin{array}{c}0.00012 \\
4\end{array}$ & 7.006 & 4.863 & 2.711 \\
\hline Bruggeman Model & 1.87 & - & 62.336 & 77.348 & 197.1 \\
\hline $\begin{array}{c}\text { Modified Bruggeman } \\
\text { Model }\end{array}$ & 58.5 & 0.00001 & 61.325 & 6.98 & 64.602 \\
\hline Pal Model & 27.3 & - & 17.144 & 48.338 & 71.378 \\
\hline Modified Pal Model & 29.6 & 0.00034 & 17.032 & 32.233 & 25.236 \\
\hline
\end{tabular}

TABLE IV: COMPARISON OF THE AARE VALUES FOR IDEAL AND MODIFIED MOdels (Using THE EXPERIMENTAL DATA OF HE, $\mathrm{N}_{2}$ PERMEATION AND HE/ $\mathrm{N}_{2}$ SELECTIVITY IN POLYSUlfone-Silica MMM at $308 \mathrm{~K}$ ) [21]

\begin{tabular}{|c|c|c|c|c|c|}
\hline Model & $\begin{array}{c}\boldsymbol{I}_{\boldsymbol{I}} \\
(\mathbf{A})\end{array}$ & $\boldsymbol{\beta}$ & \multicolumn{3}{|c|}{ AARE \% } \\
\cline { 4 - 6 } & 10.2 & - & 11.881 & 22.877 & 52.743 \\
\hline Maxwell & 24.5 & $\begin{array}{c}0.00004 \\
2\end{array}$ & 9.022 & 11.244 & 1.959 \\
\hline $\begin{array}{c}\text { Modified Maxwell } \\
\text { Model }\end{array}$ & 1.7 & - & 46.871 & 143.05 & 905.2 \\
\hline $\begin{array}{c}\text { Bruggeman Model } \\
\text { Modified Bruggeman } \\
\text { Model }\end{array}$ & 4 & 0.00095 & 36.878 & 40.933 & 9.329 \\
\hline $\begin{array}{c}\text { Pal Model } \\
\text { Modified Pal Model }\end{array}$ & 15.3 & - & 4.624 & 28.216 & 52.753 \\
\hline Men & 21.2 & 0.0001 & 4.598 & 16.427 & 26.497 \\
\hline
\end{tabular}

Table $\mathrm{V}$ indicates optimized parameters and AAREs of $\mathrm{O}_{2}$ and $\mathrm{N}_{2}$ permeabilities and $\mathrm{O}_{2} / \mathrm{N}_{2}$ selectivities through Matrimid- $\mathrm{TiO}_{2} \mathrm{MMMs}$ at $35{ }^{\circ} \mathrm{C}$. In these MMMs, as other ones, $\beta$ parameters are very smaller than one, supporting the overestimation of Knudsen flow for the formed voids. The thickness of the formed voids $\left(l_{I}\right)$ is also move to the true range of Knudsen flow and consequently AAREs are reduced for both permeability and selectivity prediction after introducing $\beta$ parameter.

TABLE V: COMPARISON OF THE AARE VALUES FOR IDEAL AND MODIFIED MODELS (USING THE EXPERIMENTAL DATA OF $\mathrm{O}_{2}, \mathrm{~N}_{2}$ PERMEATION AND $\mathrm{O}_{2} / \mathrm{N}_{2}$ SELECTIVITY IN MATRIMID-TIO ${ }_{2}$ MMM AT $308 \mathrm{~K}$ ) [22]

\begin{tabular}{|c|c|c|c|c|c|}
\hline Model & $\boldsymbol{l}_{\boldsymbol{I}}(\mathbf{\AA})$ & $\boldsymbol{\beta}$ & \multicolumn{3}{|c|}{ AARE \% } \\
\cline { 4 - 6 } & 2.1 & - & 10.158 & 42.594 & 99.231 \\
\hline Maxwell & 7.3 & 0.000005 & 6.478 & 8.178 & 14.011 \\
\hline $\begin{array}{c}\text { Modified Maxwell } \\
\text { Model }\end{array}$ & 1.9 & - & 55.817 & 73.216 & 387.17 \\
\hline $\begin{array}{c}\text { Bruggeman Model } \\
\text { Modified Bruggeman } \\
\text { Model }\end{array}$ & 9.58 & 0.00001 & 36.865 & 5.922 & 35.087 \\
\hline $\begin{array}{c}\text { Pal Model } \\
\text { Modified Pal Model }\end{array}$ & 3.4 & - & 6.629 & 43.175 & 75.013 \\
\hline M. & 4.7 & 0.001 & 6.523 & 29.128 & 46.409 \\
\hline
\end{tabular}

\section{CONCLUSION}

Knowing the permeability of gases through mixed matrix membrane is vital in industry. Due to some defects occur during MMM fabrication, the mechanism of the permeability is changed. Different models are available to predict gas permeability with regard to defects. Interface void is one of the defect. For predicting MMM's permeability, first should estimate void permeability. The estimated permeabilities for the formed voids is higher than that reported so these permeabilities is corrected by $\beta$, void permeability adjustment. The present method proved that the permeability and selectivity of gases through MMMs, could be predicted accurately (Tables II-Table V). In addition, c, the thickness of void volume layer, is also modified. Among the models studied, the modified Maxwell model gives the best predictions. The present modified model will be useful for the design of MMMs for commercial applications.

\section{REFERENCES}

[1] T. T. Moore and W. J. Koros, "Non-ideal effects in organic-inorganic materials for gas separation membranes," Journal of Molecular Structure, vol. 739, pp. 87-98, Dec. 2005.

[2] A. Shariati, M. Omidkhah, and M. Z. Pedram, "New permeation models for nanocomposite polymeric membranes filled with nonporous particles," Chemical Engineering Research and Design, vol. 90, pp. 563-575, Aug. 2012.

[3] R. W. Baker, Membrane Technology and Applications, McGraw-Hill, 2000, ch. 6, pp. 237-274.

[4] J. K. Ward, and W. J. Koros, "Crosslinkable mixed matrix membranes with surface modified molecular sieves for natural gas purification: I. Preparation and experimental results," Journal of Membrane Science, vol. 377, pp. 75-81, April 2011.

[5] D. Bastani, N. Esmaeili, and M. Asadollahi, "Polymeric mixed matrix membranes containing zeolites as a filler for gas separation applications: A review," Journal of Industrial and Engineering Chemistry, vol. 19, pp. 375-393, March 2013.

[6] T.-S. Chung et al., "Mixed matrix membranes (MMMs) comprising organic polymers with dispersed inorganic fillers for gas separation," Progress in Polymer Science, vol. 32, pp. 483-507, Feb. 2007.

[7] S. Basu, A. C. Odena, and I. F. J. Vankelecom, "Asymmetric Matrimid®/[Cu3(BTC)2] mixed-matrix membranes for gas separations," Journal of Membrane Science, vol. 362, pp. 478-487, Aug. 2010.

[8] M. A. Aroon et al., "Performance studies of mixed matrix membranes for gas separation: A review," Separation and Purification Technology, vol. 75, pp. 229-242, Aug. 2010.

[9] R. Pal, "Permeation models for mixed matrix membranes," Journal of Colloid and Interface Science, vol. 317, pp. 191-198, Sep. 2008.

[10] T. Li et al., "Carbon dioxide selective mixed matrix composite membrane containing ZIF-7 nano-fillers," Journal of Membrane Science, vol. 425-426, pp. 235-242, Jan. 2013.

[11] B. Shimekit, H. Mukhtar, and T. Murugesan, "Prediction of the relative permeability of gases in mixed matrix membranes," Journal of Membrane Science, vol. 373, pp. 152-159, March 2011.

[12] S. A. Hashemifard, A. F. Ismail, and T. Matsuura, "Prediction of gas permeability in mixed matrix membranes using theoretical models," Journal of Membrane Science, vol. 347, pp. 53-61, Oct. 2010.

[13] S. A. Hashemifard, A. F. Ismail, and T. Matsuura, "A new theoretical gas permeability model using resistance modeling for mixed matrix membrane systems," Journal of Membrane Science, vol. 350, pp. 259-268, Jan. 2010.

[14] D. Q. Vu, W. J. Koros, and S. J. Miller, "Mixed matrix membranes using carbon molecular sieves: II. Modeling permeation behavior," Journal of Membrane Science, vol. 211, pp. 335-348, Sep. 2003.

[15] K. M. Gheimasi, T. Mohammadi, and O. Bakhtiari, "Modification of ideal MMMs permeation prediction models: Effects of partial pore blockage and polymer chain rigidification," Journal of Membrane Science, vol. 427, pp. 399-410, Oct. 2013.

[16] A. J. Petsi and V. N. Burganos, "Interphase layer effects on transportin mixed matrix membranes," Journal of Membrane Science, vol. 421-422, pp. 247-257, July 2012.

[17] B. Shimekit, H. Mukhtar, and S. Maitra, "Comparison of Predictive Models for Relative Permeability of $\mathrm{CO}_{2}$ in Matrimid-Carbon Molecular Sieve Mixed Matrix Membrane," Journal of Applied Sciences, vol. 10, pp. 1204-1211, 2010.

[18] S. S. Hosseini et al., "Enhanced gas separation performance of nanocomposite membranes using $\mathrm{MgO}$ nanoparticles," Journal of Membrane Science, vol. 302, pp. 207-217, 2007. 
[19] A. B. Shelekhin, A. G. Dixon, and Y. H. Ma, "Adsorption, permeation, and diffusion of gases in microporous membranes. II. Permeation of gases in microporous glass membranes," Journal of Membrane Science, vol. 75, pp. 233-244, Aug. 1992.

[20] T. Kono, Y. Hu, T. Masuda, K. Tanaka, R. D. Priestley, and B. D. Freeman, "Effect of Fumed Silica Nanoparticles on the Gas Permeation Properties of Substituted Polyacetylene Membranes," Polymer Bulletin, vol. 58, pp. 995-1003, Dec. 2007.

[21] J. Ahn et al., "Polysulfone/silica nanoparticle mixed-matrix membranes for gas separation," Journal of Membrane Science, vol. 314 pp. 123-133, Jan. 2008

[22] F. Moghadam et al., "The effect of $\mathrm{TiO} 2$ nanoparticles on gas transport properties of Matrimid5218-based mixed matrix membranes," Separation and Purification Technology, vol. 77, pp. 128-136, Nov. 2011.

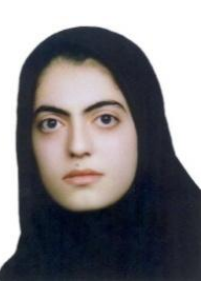

Nasrin Sadeghi was born at Kermansha, Iran, in September 1988 and got master in chemical engineering, Razi university, Kermanshah, Iran, since 2011, Bachelor in chemcial engineering, Razi university, Kermanshah, Iran, 2006-2010, Diploma in Mathematics, Mofateh highschool, Kermanshah, Iran, 2003-2006. She is a member of the Iranian Engineers' Club, Ranked $2^{\text {nd }}$ among the graduates of the academic in Master of Science degree, Ranked first among graduates of the school in Diploma degree, cooperation with the $8^{\text {th }}$ National collegian Chemical Engineering Congress, Participating in overhaul time at KPIC company, 2010 .

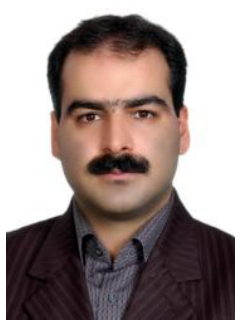

Omid Bakhtiari is an assiatant professor of chemical, engineering, Ph.D. in chemical engingeering, chemical engineering department, IUTS, Narmak, Tehran, Iran, 2005 - 2009. Master in chemical engineering, chemical engineering , IUTS, Narmak, Tehran, Iran, 2003 - 2005. Bachelor in chemical, Razi university, Kermanshah, Iran, 1999-2003. He is member of Iranian chemical engineering asociation, working professionally on the membrane gas separation: modeling and experimentally. 